\title{
ZnO:Al Grown by Sputtering from Two Different Target Sources: A Comparison Study
}

\author{
Abdalla A. Alnajjar \\ Applied Physics Department, College of Sciences, University of Sharjah, P.O. Box 27272, Sharjah, United Arab Emirates \\ Correspondence should be addressed to Abdalla A. Alnajjar, an@astf.net \\ Received 1 June 2011; Accepted 5 January 2012 \\ Academic Editor: Jörg Fink \\ Copyright () 2012 Abdalla A. Alnajjar. This is an open access article distributed under the Creative Commons Attribution License, \\ which permits unrestricted use, distribution, and reproduction in any medium, provided the original work is properly cited. \\ Al-doped $\mathrm{ZnO}$ thin films were deposited from two different targets. Ceramic targets were used in RF magnetron sputtering, \\ whereas pulsed magnetron sputtering was used to grow films from powder targets. ZnO:Al films with different thicknesses were \\ sputtered directly on soda-lime glass substrates. The film thickness was in the $0.04-2.0 \mu \mathrm{m}$ range. The microstructure, such as \\ the grain size and the texture, of the two differently grown $\mathrm{ZnO}: \mathrm{Al}$ transparent conductive oxide films of different thickness, was \\ studied using X-ray diffraction $\theta / 2 \theta$ scans. The optical properties, such as the transmittance and reflectance, were measured using \\ a UV-Vis-NIR spectrometer. Further, the sheet resistance, resistivity, carrier concentration, and Hall mobility of these $\mathrm{ZnO}$ :Al thin \\ films were measured as a function of film thickness. These results obtained from the two different deposition techniques were com- \\ pared and contrasted.
}

\section{Introduction}

Recently, zinc oxide $(\mathrm{ZnO})$ thin films have received increasing attention as an alternative window material for photovoltaic cell applications where low-resistance and transparent films are required. Aluminum-doped $\mathrm{ZnO}$ ( $\mathrm{ZnO}: \mathrm{Al})$ thinfilm transparent conductive oxides (TCOs) are excellent candidates for a transparent front contact for solar cells. Further, TCO films have found extensive applications in optoelectronic devices (e.g., solar cells, liquid-crystal displays, heat mirrors, and multiplayer photothermal conversion systems). Zinc oxide has attracted attention as a TCO because of its (i) large bandgap $(3.3 \mathrm{eV})$, (ii) high conductivity, (iii) ease in doping, (iv) thermal stability when doped with group III elements, and (v) abundance in nature and nontoxicity. In addition to potential use as a TCO in optoelectronic devices, $\mathrm{ZnO}$ thin films also find application as gas sensors because of their high electrical resistivity. The optoelectronic properties of $\mathrm{ZnO}$ thin films depend on the deposition and postdeposition treatment conditions because these properties change significantly with the (i) nature of chosen doping element, (ii) adsorption of oxygen that occurs during film deposition, (iii) film deposition temperature, and (iv) desorption during annealing treatment in a reducing atmosphere.
Several deposition techniques are used to grow $\mathrm{ZnO}: \mathrm{Al}$ thin films, including chemical vapor deposition (CVD) [1], spray pyrolysis [2,3], pulsed laser deposition (PLD) [4], and magnetron sputtering [5-7]. Compared to other techniques, magnetron sputtering has many advantages, such as (i) sputter cleaning of the substrate in vacuum prior to film deposition can be done; (ii) the composition of the films grown is quite close to that of the target; (iii) the surface of the films is very smooth; (iv) film thickness is easily controlled by fixing the operating parameters and simply adjusting the deposition time; (v) it can easily be scaled to obtain large-area films for practical applications.

The aim of this paper is to show the effect of the different targets, ceramic and powder, used with magnetron sputtering techniques, on the properties of the grown films. Films with different thicknesses of $\mathrm{ZnO}: \mathrm{Al}$ were prepared and analyzed for their structural, transmittance, and electrical properties.

\section{Experimental Procedure}

2.1. Growth. ZnO:Al films were deposited from two different targets. Ceramic targets were used in RF magnetron sputtering, whereas pulsed magnetron sputtering was used to grow 
films from powder targets. ZnO:Al films with different thicknesses were sputtered directly on soda-lime glass substrates. The film thickness was in the $0.04-2.0 \mu \mathrm{m}$ range.

2.1.1. RF Sputtering from Ceramic Targets. Conductive $\mathrm{ZnO}$ films were deposited directly on soda-lime glass substrates by $\mathrm{RF}$ sputtering from a compound $\mathrm{ZnO}: \mathrm{Al}_{2} \mathrm{O}_{3}$ target with $2 \%$ $\mathrm{Al}_{2} \mathrm{O}_{3}$ by weight. The film thicknesses were $0.04,0.1,1.0$, and $2.0 \mu \mathrm{m}$. Table 1 shows the sputtering conditions in detail. The substrate temperature was difficult to maintain at a constant level during the deposition, due to gradual increase from room temperature to about $400 \mathrm{~K}$ (the nature of sputtering operation required bombardment with high-energetic electron which bound to increase the substrate temperature).

2.1.2. Pulsed Magnetron Sputtering from Powder Targets. The $\mathrm{ZnO}$ :Al films were deposited in a system specifically designed for powder target use [8]. A single $180 \mathrm{~mm}$-diameter highfield-strength unbalanced magnetron was installed in the base plate of the chamber in the "sputter-up" configuration. The substrate holder was positioned directly above the magnetron, at a separation of $120 \mathrm{~mm}$. The substrate holder could be RF biased (Advanced Energy RFX600), if required. A $1 \mathrm{~kW}$ radiant heater was also installed in the rig, which could be positioned, after deposition, to face the coated substrate. This allowed annealing of the coatings to occur in controlled atmospheres at substrate temperatures of up to $500^{\circ} \mathrm{C}$. Finally, a dummy magnetron was installed in the chamber roof vertically opposed to the magnetron. This dummy device only included an outer ring of magnets and was installed to produce a closed magnetic field across the chamber. The intention here was to enhance film structure and properties by maximizing the ion-to-atom ratio incident at the substrate $[9,10]$.

The powder blends were made by mixing appropriate quantities of $99.99 \%$ pure zinc oxide and aluminum oxide powders in a rotating drum for several hours. For each material, the particles were typically a few micrometers in diameter. Initially, batches were produced with a dopant concentration of $4 \mathrm{wt} \%$ alumina. Following blending, about $60 \mathrm{~g}$ of powder were evenly distributed across the surface of a copper backing plate on the magnetron to form a target. The backing plate was recessed to a depth of $2 \mathrm{~mm}$ to allow a reasonable target thickness to be produced. The powder was lightly tamped to produce a uniform thickness and surface to target distance. No further processes were involved in target production.

The $\mathrm{ZnO}$ films were deposited onto soda-lime silicate glass microscope slides. The substrates were precleaned using a proprietary glass cleaner ("Windolene") before loading into the chamber and RF being sputter-cleaned at $250 \mathrm{~W}$ for $30 \mathrm{~min}$ prior to deposition. The magnetron driver was a $10 \mathrm{~kW}$ Advanced Energy Pinnacle Plus supply, operated in current-regulation mode (target current $=2 \mathrm{~A}$ ) at a pulse frequency of $350 \mathrm{kHz}$ (62\% duty). During sputtering, the argon flow rate was fixed at $30 \mathrm{sccm}$. Oxygen was also introduced into the chamber at a flow rate of $2.4 \mathrm{sccm}$, to maintain the required coating stoichiometry. The coating pressure was
TABLE 1: RF sputtering conditions for deposition of $\mathrm{ZnO}$ films from ceramic targets.

\begin{tabular}{lc}
\hline Deposition parameter & Conditions \\
\hline R.F. power $\left(\mathrm{W}_{\mathrm{Ar}}\right)$ & $200 \mathrm{~W}$ \\
Presputtering & $5 \mathrm{~min}$ before each deposition \\
Base pressure & $5 \times 10^{-6}$ torr \\
Argon pressure $\left(\mathrm{P}_{\mathrm{Ar}}\right)$ & $5 \mathrm{mtorr}$ \\
Substrate temperature & Unheated and no control \\
Target-to-substrate distance & $11.5 \mathrm{~cm}$ \\
\hline
\end{tabular}

0.4 Pa. Run times varied from 1 to $4 \mathrm{~h}$, depending on the coating thickness required. Following deposition, the coatings received no further treatment.

2.2. Characterization. The microstructure, such as the grain size and the texture, of the two differently grown $\mathrm{ZnO}: \mathrm{Al}$ TCO thin films was studied. We examined the texture of the $\mathrm{ZnO}: \mathrm{Al}$ samples of different thickness using the X-ray diffraction $\theta / 2 \theta$ technique. Also, we calculated the grain size of the ZnO:Al films by using Peak Fit V3.0 software and by measuring the broadening of the diffraction lines measured at half-maximum intensity. The grain size can be calculated by using Scherrer's equation [11], given by

$$
t=\frac{0.9 \lambda}{[\beta \cos (\theta)]},
$$

where $t$ is the diameter of the crystallite in the direction perpendicular to the planes that generate the diffraction lines at the Bragg angle $2 \theta$. $\beta$ is the broadening of the diffraction line measured at half-maximum intensity in radians and given by

$$
\beta^{2}=\beta_{M}^{2}+\beta_{S}^{2}
$$

where $\beta_{S}$ is the measured breadth at half-maximum intensity of the line from a standard and $\beta_{M}$ is the measured breadth at half-maximum intensity of the line from the $\mathrm{ZnO}: \mathrm{Al}$ thin film. LiB6 powder (from NIST) was used as a standard material.

The optical properties, such as the transmittance and reflectance, were measured using a UV-vis-NIR spectrometer. Measurements were also done for the electrical properties, such as resistivity, mobility, and carrier concentration, using a Bio-Rad Hall measurement system.

The transmittance and the reflectance curves were measured using a UV-vis-NIR spectrometer at NREL. The absorbance was calculated using the following equation:

$$
A=100-R-T,
$$

where $A$ is the percent absorbance, $T$ is the percent transmittance, and $R$ is the percent reflectance. From the slope of the absorption curve near the band edge in the Tauc equation [12],

$$
(\alpha h v)^{2}=B\left(h v-E_{g}\right)
$$




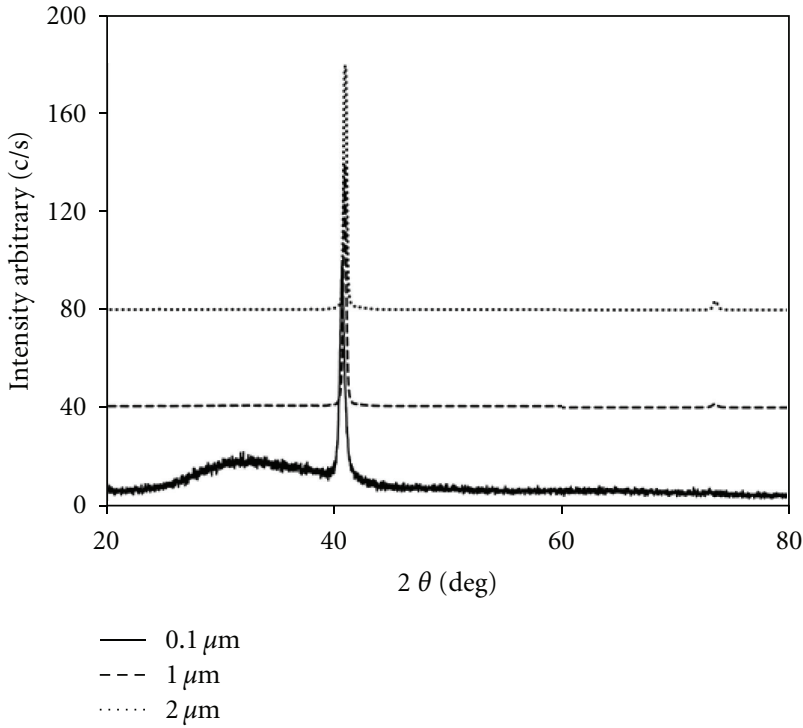

Figure 1: $\theta / 2 \theta$ XRD scans of $\mathrm{ZnO}$ :Al films with different thicknesses, grown from ceramic targets.

It is possible to determine the energy gap $\left(E_{g}\right)$ by plotting $(\alpha h \nu)^{2}$ versus photon energy $(h \nu)$ then taking a straight-line relationship at high absorption data $\left(\alpha>10^{4} \mathrm{~cm}^{-1}\right)$. The zero intercept at $\alpha=0$ gives the energy gap for direct transition.

One important optical characterization of TCOs is that they have a transmission window between wavelengths of about 0.4 and $1.5 \mu \mathrm{m}$. At wavelengths shorter than $0.4 \mu \mathrm{m}$, absorption occurs due to the fundamental bandgap; thus, light cannot be transmitted due to a quantum phenomenon. At longer wavelengths, reflection occurs because of the plasma edge, and light cannot be transmitted due to a classical phenomenon. The wavelengths at which these transitions occur are determined by a number of fundamental characteristics, as well as by the concentration of free electrons.

\section{Results and Discussion}

\subsection{RF Sputtering from Ceramic Targets}

3.1.1. Structural Properties. X-ray $\theta / 2 \theta$ diffraction patterns revealed that all $\mathrm{ZnO}: \mathrm{Al}$ films exhibit a strong $\langle 002\rangle$ texture parallel to the growth direction (absent or weak diffraction from other planes). Figure 1 shows the X-ray diffraction pattern corresponding to (002) planes for the three $\mathrm{ZnO}: \mathrm{Al}$ films of different thickness, as indicated in the figure. A small shift is observed in the center of the peak upon going from the thinnest to the thickest film. By calculating the "c" lattice constant for the (002) plane, we found that this lattice constant was $5.252 \AA$ for the $0.1 \mu \mathrm{m}$-thick film, whereas it was $5.206 \AA$ for the $2 \mu \mathrm{m}$-thick film. This result could be due to either a residual stress difference with thickness or the higher incorporation of $\mathrm{Al}$ in the thicker films as indicated by the higher carrier concentration.

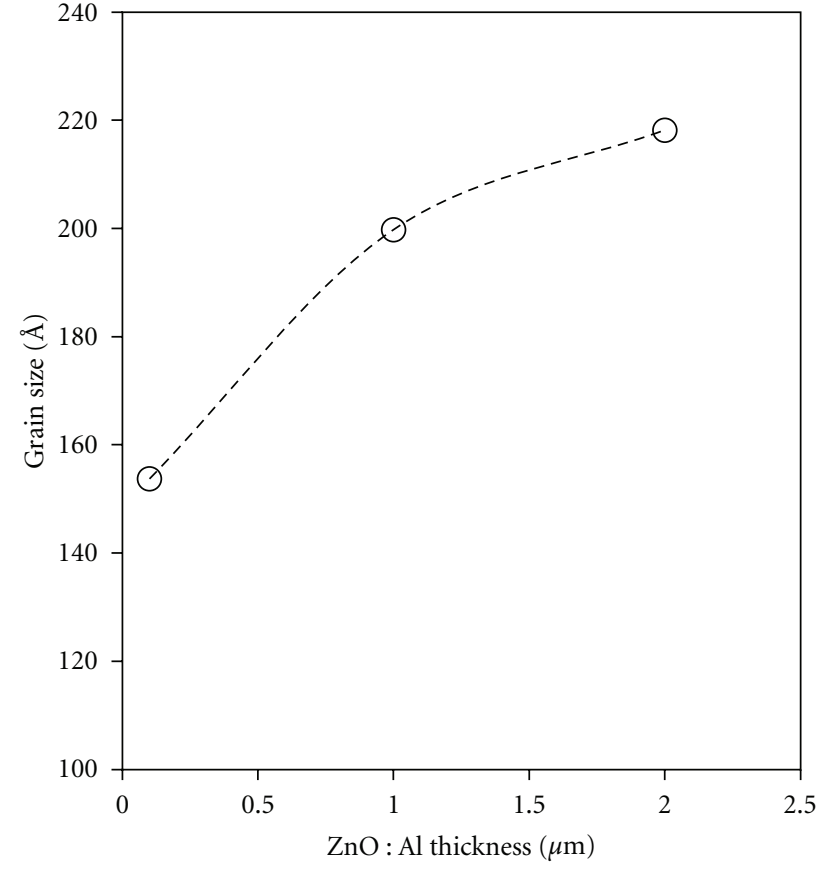

Figure 2: Calculated grain size for the $\mathrm{ZnO}: \mathrm{Al}$ films grown from ceramic target.

By measuring the width at half maximum of the above diffraction lines for (002) planes shown in Figure 1, as well as for the diffraction lines corresponding to the powder standard sample, we could calculate the diameter of the crystallites. Figure 2 shows the grain diameter (in $\AA$ ) versus the $\mathrm{ZnO}: \mathrm{Al}$ film thickness. The grain size is $15 \mathrm{~nm}$ for the $0.1 \mu \mathrm{m}$ film thickness, then increases up to $22 \mathrm{~nm}$ with increasing film thickness. This means that a disorder of the grain size is elevated, and this will lead to a polycrystalline film structure.

For a randomly oriented powder $\mathrm{ZnO}$ sample [12], the "c" lattice constant is $5.2066 \AA$. The slightly higher measured lattice constant indicates that the films are under compressive stress, which may be due either to (i) lattice expansion in the growing films induced by energetic incorporated working Ar gas that bombards the growing $\mathrm{ZnO}: \mathrm{Al}$ films by atomic peening action [13], or (ii) another mechanism related to $\mathrm{Al}$ incorporation mentioned above. Also, a decrease in grain size correlates well with the increase in strength and hardness [11].

3.1.2. Optical and Electrical Properties. Figure 3 shows the transmittance and reflectance of the four films with different thickness, and Figure 4 shows the corresponding absorbance curves. Some features in these graphs are worth noting. First, there is a sharp increase in the transmittance as the wavelength of light increases above $350-400 \mathrm{~nm}$, with a corresponding dramatic decrease in the absorption, as shown in Figure 4. This is due to the absorption at the optical bandgap, where for the $\mathrm{ZnO}$ direct semiconductor, the minimum energy gap is $3.2 \mathrm{eV}(388 \mathrm{~nm})$ at room temperature [14]. Second, a slow decrease can be noticed in the transmittance starting at $1000 \mathrm{~nm}$ for the two thicker samples, with 


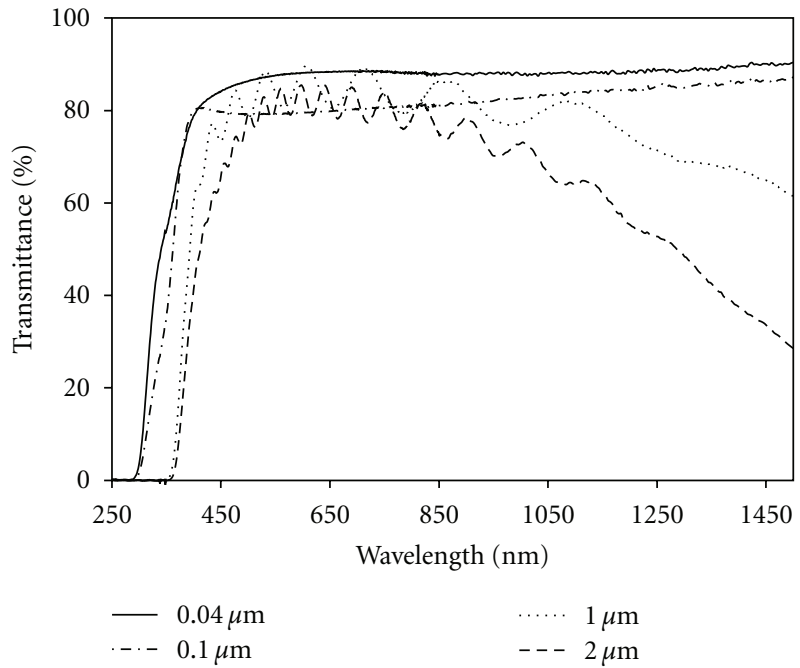

(a)

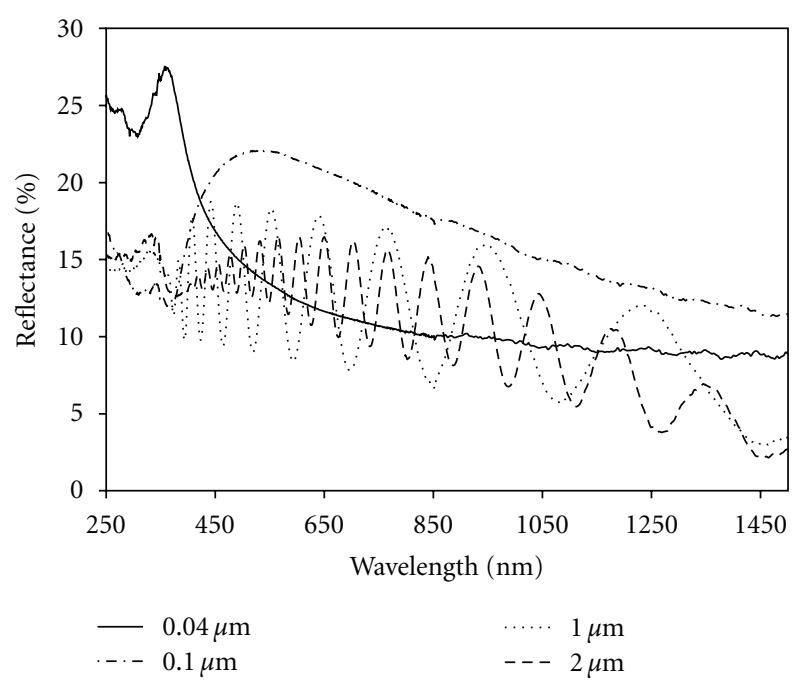

(b)

Figure 3: (a) Transmittance and (b) reflectance data for the $\mathrm{ZnO}: \mathrm{Al}_{2} \mathrm{O}_{3}$ films of different thickness.

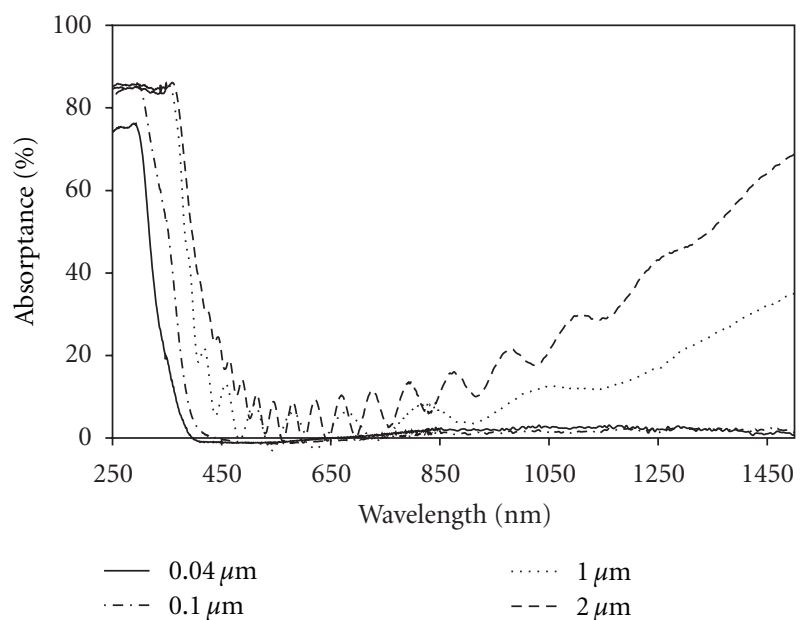

Figure 4: Absorbance data for the $\mathrm{ZnO}: \mathrm{Al}_{2} \mathrm{O}_{3}$ films of different thickness.

a gradual increase in the absorbance. Third, the region of transparency is reduced on the long-wavelength side for the films with higher carrier concentration (see Table 1). Sernelius et al. [15] discussed such a shift and asserted that the optical bandgap of a heavily doped semiconductor can be larger or smaller than that of the undoped host crystal. The former is due to the Burstein-Moss effect. The latter can also happen, which may be due to the effects of strain or stress and other types of imperfections. We believe that our observations are related to the latter effect. The XRD results of this work indicate that the films are under more compressive stress with increasing the thickness. Many TCOs exhibit such a shift in optical bandgap [16].

Table 2 shows the sheet resistance, resistivity, carrier concentration, and Hall mobility of $\mathrm{ZnO}: \mathrm{Al}$ thin films as a function of film thickness. As the latter increases, the electrical
TABLE 2: Measured electrical properties for $\mathrm{ZnO}: \mathrm{Al}_{2} \mathrm{O}_{3}$ films grown from ceramic targets.

\begin{tabular}{lcccc}
\hline $\begin{array}{l}\text { Thickness } \\
(\mu \mathrm{m})\end{array}$ & $\begin{array}{c}\text { Sheet } \\
\text { resistance } \\
(\Omega / \square)\end{array}$ & $\begin{array}{c}\text { Resistivity } \\
(\Omega \cdot \mathrm{cm})\end{array}$ & $\begin{array}{c}\text { Mobility } \\
\left(\mathrm{cm}^{2} / \mathrm{V} \cdot \mathrm{s}\right)\end{array}$ & $\begin{array}{c}\text { Carrier con- } \\
\text { centration } \\
\left(1 / \mathrm{cm}^{3}\right)\end{array}$ \\
\hline 0.04 & $3.75 \times 10^{5}$ & 1.49 & 0.4 & $-1.05 \times 10^{19}$ \\
0.1 & $5.71 \times 10^{3}$ & 0.0571 & 1.5 & $-7.30 \times 10^{19}$ \\
1.0 & 24.4 & 0.00244 & 5.46 & $-4.69 \times 10^{20}$ \\
2.0 & 7.15 & 0.00143 & 10.3 & $-4.25 \times 10^{20}$ \\
\hline
\end{tabular}

characteristics become more pronounced favorably for TCO. The resistivity is proportional to the reciprocal of the product of the carrier concentration $(N)$ and the mobility $(\mu)$. Therefore, the change in resistivity is ascribed to the change in $N$ and/or $\mu$, which are characteristic parameters reflecting the film stoichiometry and/or the impurity contents. As we mentioned before when the thicknesses of films increased the grain size increased which caused that mobility and carrier concentration increased.

\subsection{Pulsed Magnetron Sputtering from Powder Targets}

3.2.1. Structural Properties. The coatings grown from powder source were also subjected to structural and composition tests. Electron probe microanalysis (EPMA) indicated that the coatings contained about $2 \mathrm{wt} \%$ aluminum compared to $4 \mathrm{wt} \%$ aluminum in the target. The same technique is not able to determine the stoichiometry of the films, as it does not quantitatively measure oxygen. Table 3 shows the relationship between the aluminum concentration in the target $\left(\mathrm{Al}_{2} \mathrm{O}_{3}\right)$ and $\mathrm{Al}$ in the coatings for three different film thicknesses.

In an earlier publication on these films [17], scanning electron microscopy (SEM) images of a fractured section of 
TABLE 3: EPMA analysis of composition of $\mathrm{Al}$ in coatings compared to that in powder target.

\begin{tabular}{lcc}
\hline $\begin{array}{l}\text { Film thickness } \\
(\mu \mathrm{m})\end{array}$ & $\begin{array}{c}\text { Powder blend } \\
\left(\text { wt } \% \mathrm{Al}_{2} \mathrm{O}_{3}\right)\end{array}$ & $\begin{array}{c}\mathrm{Al} \text { in the film } \\
(\mathrm{wt} \%)\end{array}$ \\
\hline 0.1 & 2 & 0.5 \\
1.0 & 4 & 1.5 \\
2.0 & 4 & 2.5 \\
\hline
\end{tabular}

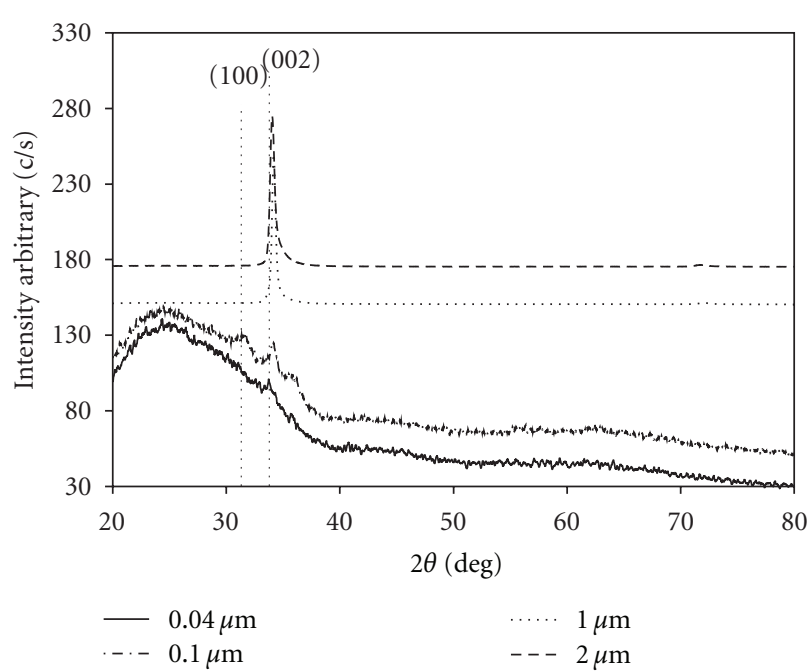

FIgure 5: XRD $\theta / 2 \theta$ scans for $\mathrm{ZnO}$ :Al films grown from powder source with different thickness.

a typical film showed dense columnar structure and appeared to be free of voids. The X-ray $\theta / 2 \theta$ diffraction patterns revealed that these $\mathrm{ZnO}$ :Al films exhibit a strong $\langle 002\rangle$ texture. Weak $\langle 100\rangle$ diffraction is observed with thinner samples. Figure 5 shows the $\mathrm{X}$-ray diffraction pattern for three $\mathrm{ZnO}$ :Al films of different thicknesses. A small shift occurs in the center of the peak from the thinnest to the thickest film.

We calculated the diameter of the crystallites by measuring the width at half maximum of the above diffraction lines for (002) planes shown in Figure 5, as well as for the diffraction lines corresponding to the powder standard sample. Figure 6 shows the grain diameter (in $\AA$ ) versus the $\mathrm{ZnO}: \mathrm{Al}$ film thickness. The grain size is $4.5 \mathrm{~nm}$ for the $0.04-\mu \mathrm{m}$ film thickness, then increases up to $18.5 \mathrm{~nm}$ for the $2-\mu \mathrm{m}$ film.

3.2.2. Optical and Electrical Properties. The transmittance and reflectance of the four films with different thicknesses were shown in Figure 7, while Figure 8 shows the corresponding absorbance curves. The following features in these graphs are worth noting. In the wavelength regime above $350-400 \mathrm{~nm}$, there is a marked increase in the transmittance, with a corresponding dramatic decrease in the absorption, as shown in Figure 8. These observations are attributed to the absorption at the optical bandgap, where for the $\mathrm{ZnO}$ direct semiconductor, the minimum energy gap is $3.2 \mathrm{eV}(388 \mathrm{~nm})$ at room temperature [14]. Furthermore, a slow decrease can be noticed in the transmittance starting at $1000 \mathrm{~nm}$ for
TABLE 4: Measured electrical properties for $\mathrm{ZnO}: \mathrm{Al}_{2} \mathrm{O}_{3}$ films grown from powder source.

\begin{tabular}{lcccc}
\hline $\begin{array}{l}\text { Thickness } \\
(\mu \mathrm{m})\end{array}$ & $\begin{array}{c}\text { Sheet } \\
\text { resistance } \\
(\Omega / \square)\end{array}$ & $\begin{array}{c}\text { Resistivity } \\
(\Omega \cdot \mathrm{cm})\end{array}$ & $\begin{array}{c}\text { Mobility } \mu \\
\left(\mathrm{cm}^{2} / \mathrm{V} \cdot \mathrm{s}\right)\end{array}$ & $\begin{array}{c}\text { Carrier con- } \\
\text { centration } N \\
\left(1 / \mathrm{cm}^{3}\right)\end{array}$ \\
\hline 1.0 & 135 & 0.0135 & 7.56 & $6.12 \times 10^{19}$ \\
2.0 & 48.4 & 0.00967 & 3 & $-2.15 \times 10^{20}$ \\
\hline
\end{tabular}

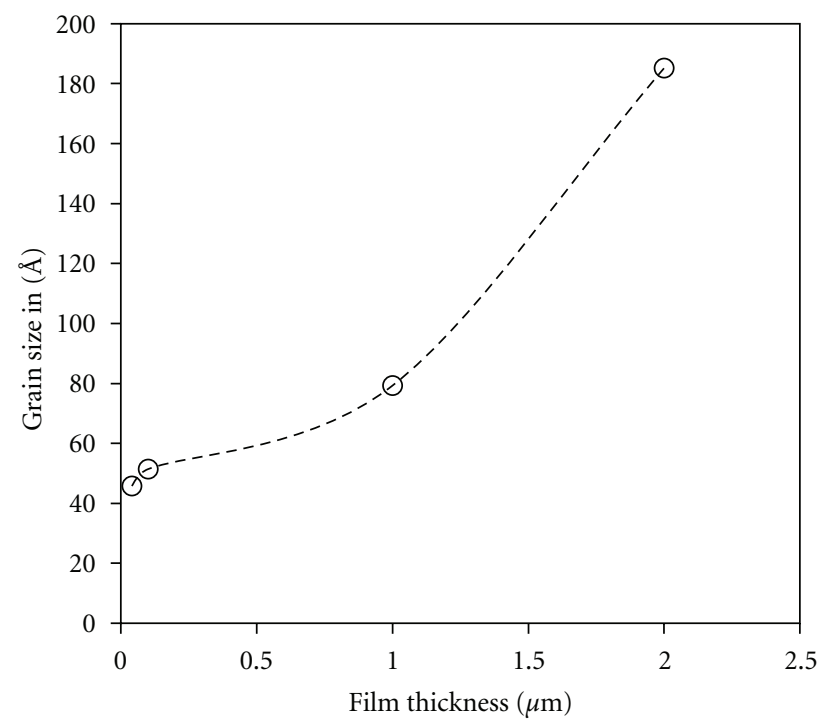

Figure 6: Calculated grain size for the $\mathrm{ZnO}$ :Al films grown from powder target.

the two thicker samples, with a gradual increase in the absorbance. Third, the region of transparency is reduced on the long-wavelength side for the higher carrier concentration.

Table 4 shows the sheet resistance, resistivity, carrier concentration, and Hall mobility of $\mathrm{ZnO}: \mathrm{Al}$ thin films grown from a powder target as a function of thickness. When the thicknesses of films decreased from 2.0 to $1.0 \mu \mathrm{m}$ the type of carrier changed from $\mathrm{n}$ - to $\mathrm{p}$-type. No meaningful readings were obtained for thinner coatings $(0.04$ and $0.1 \mu \mathrm{m})$.

\section{Summary and Comparison}

4.1. Structural Characteristics. Aluminum-doped zinc oxide films were grown from two different targets: ceramic targets were used in RF magnetron sputtering, whereas pulsed magnetron sputtering was used to grow films from powder targets. Films with different thicknesses were directly sputtered on soda-lime glass substrates.

Grazing angle X-ray diffraction was used to investigate the structural properties of these films. The angle was varied from 0.2 to 5.0 degrees, while all other parameters were kept constant. A film thickness of $1 \mu \mathrm{m}$ was used in theses studies. The X-ray scans revealed that all $\mathrm{ZnO}: \mathrm{Al}$ films exhibit a strong $\langle 002\rangle$ texture. Figures 9 (a) and 9(b) show the X-ray diffraction patterns at different angles (film depth) for 1.0$\mu \mathrm{m}$ films deposited by the two techniques. Both show a clear 


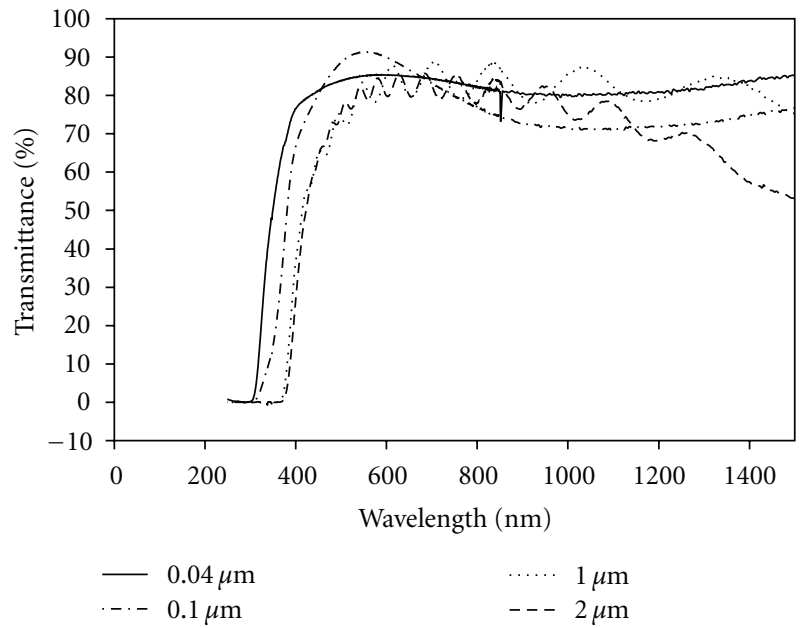

(a)

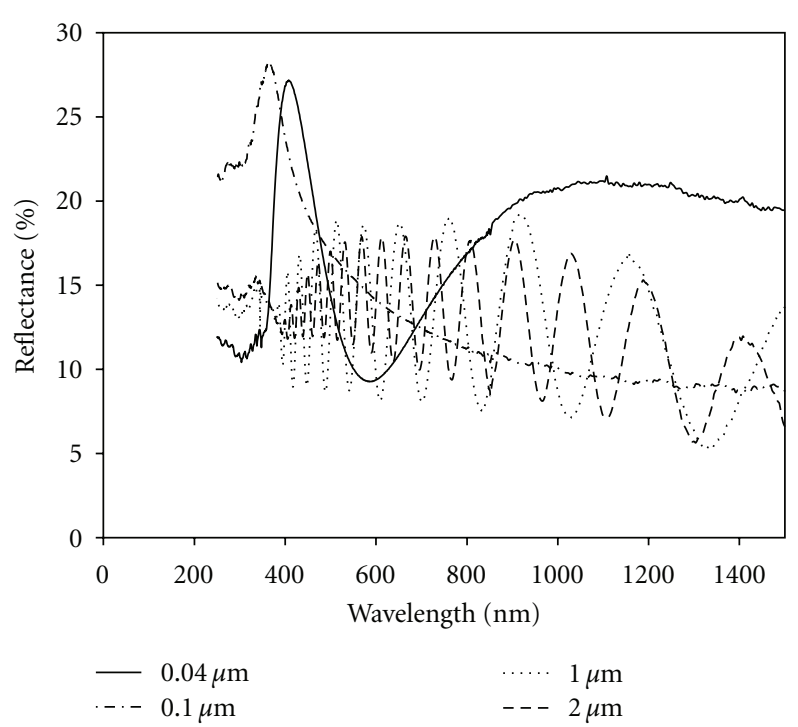

(b)

Figure 7: Transmittance and reflectance data for the $\mathrm{ZnO}: \mathrm{Al}_{2} \mathrm{O}_{3}$ films grown from powder targets at different thickness.

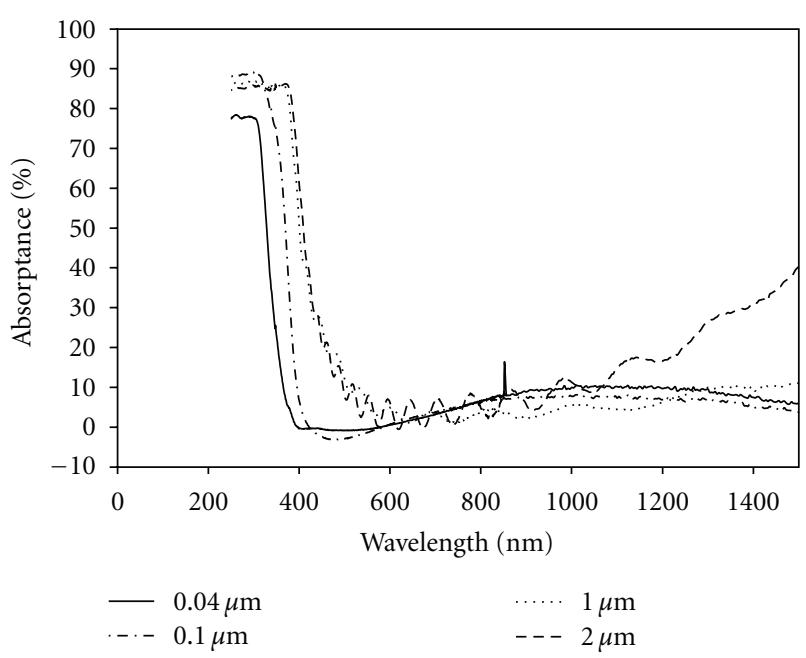

Figure 8: Absorption coefficient calculated data for the above $\mathrm{ZnO}: \mathrm{Al}_{2} \mathrm{O}_{3}$ films.

$\langle 103\rangle$ pattern close to the surface that decreases as the X-ray penetrates deeper into the bulk of the film. It is clear that closer to the film surface, the $\langle 103\rangle$ texture is more dominant in the films from ceramic targets than those of the powder targets. In all cases, small shifts in the position of the peaks are observed from the thinnest to the thickest films.

4.2. Optical Characteristics. Figure 10 shows the transmittance of four films, two of each growth technique but with different film thicknesses. Some features in these graphs are worth noting. The films show typical optical characteristics of TCOs, whereas they have a transmission window in the 0.4-1.5 $\mu \mathrm{m}$ wavelength range. The average transmittance for films deposited by both techniques decreased as the film thickness was increased from $1.0 \mu \mathrm{m}$ to $2.0 \mu \mathrm{m}$. However, there is a sharp increase in the transmittance as the wavelength of light increases between 350 and $400 \mathrm{~nm}$ for the $1.0 \mu \mathrm{m}$ film grown from the ceramic target by RF sputtering, and a rapid decrease in transmittance of the $2.0 \mu \mathrm{m}$ film grown by the same technique. The latter occurs at longer wavelengths because of the plasma edge, and light cannot be transmitted due to a classical phenomenon.

Figure 11 shows optical transmission (300-500 nm) as a function of wavelength for $\mathrm{ZnO}$ films of two different thicknesses prepared by the two different magnetron sputtering techniques. The shift in absorption edge is likely to be due residual compressive stress in the films. This change in absorption edge (small bandgap narrowing) is important in window-layer coating because it can help prevent unwanted absorption in the luminous spectra range.

Figure 12 shows the variation of the direct energy gap $\left(E_{g}\right)$ of $\mathrm{ZnO}$ films grown from ceramic and powder targets with different thicknesses. It is observed that $E_{g}$ of $\mathrm{ZnO}$ films is decreased by about $0.6 \mathrm{eV}$ as the thickness increases from $40 \mathrm{~nm}$ to $2000 \mathrm{~nm}$ for both growth methods. A possible interpretation of this decrease may be an increase in the localized density of states within the energy gap. This causes a shift to lower energy gap, that is, higher wavelength. An important observation is that the value and trend of $E_{g}$ for both growth methods are almost the same.

4.3. Electrical Characteristics. All transparent conducting $\mathrm{ZnO}$ films have n-type conductivity. The high conductivity of these films results mainly from stoichiometric deviation. The conduction electrons in these films are supplied from donor sites associated with oxygen vacancies or excess metal ions. These donor sites can be easily created by chemical reduction or intentional doping. Electrons generated from $\mathrm{O}$ 


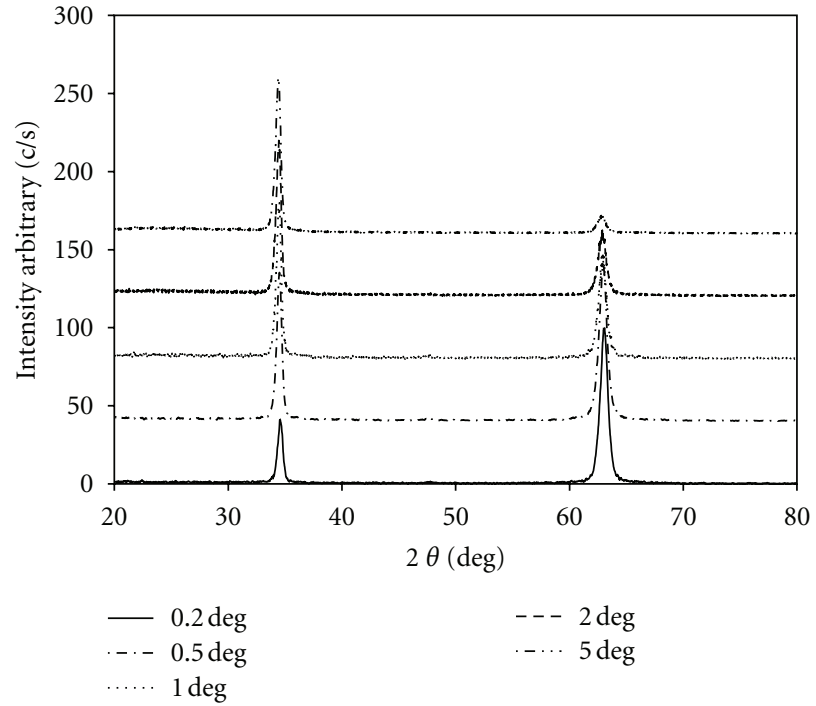

(a)

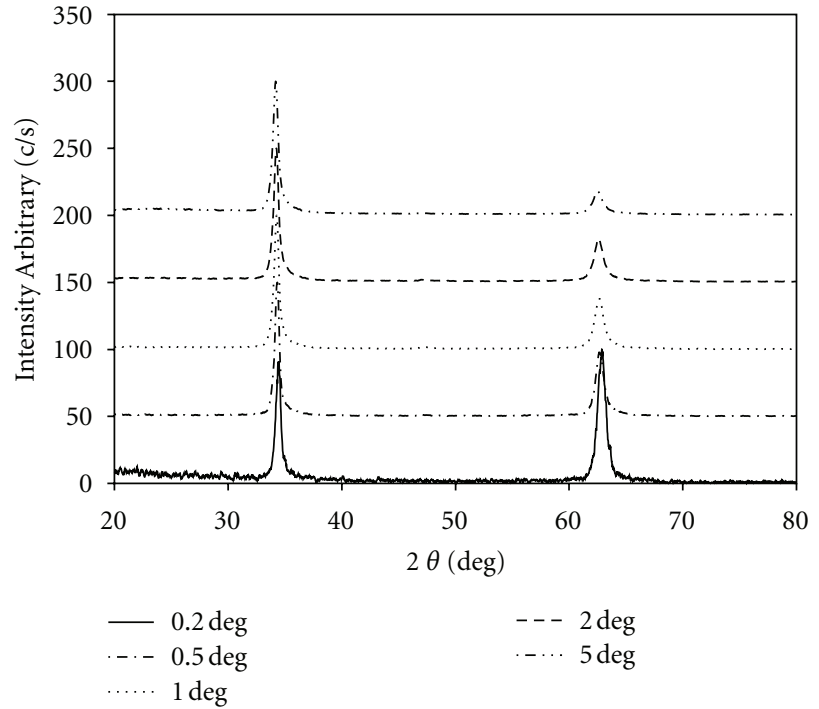

(b)

Figure 9: Grazing angle $\theta / 2 \theta$ XRD scans taken at different angles for thin films grown from (a) ceramic targets. Film thickness is $1.0 \mu \mathrm{m}$ (b) powder targets. Film thickness is $1.0 \mu \mathrm{m}$.

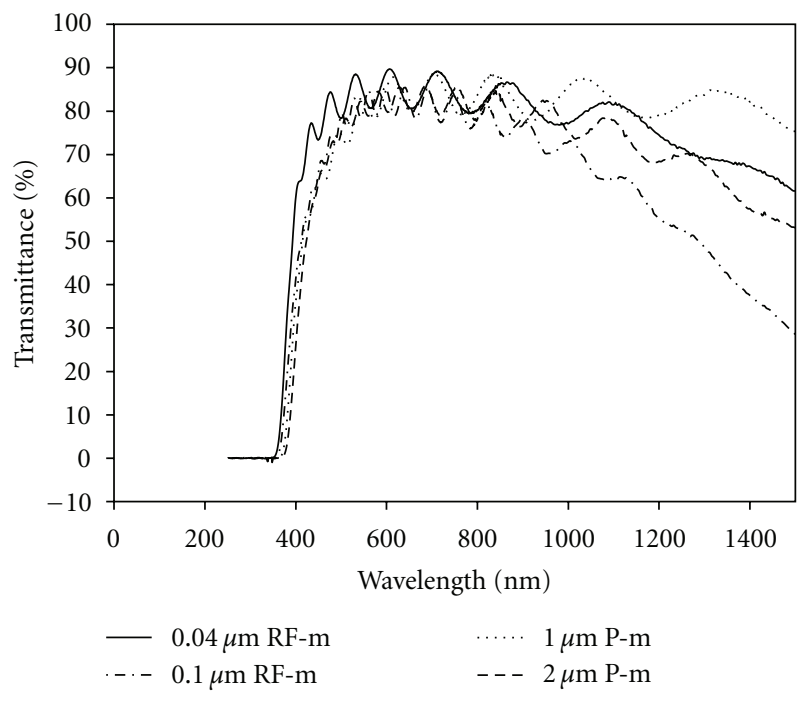

Figure 10: Transmittance for the $\mathrm{ZnO}: \mathrm{Al}_{2} \mathrm{O}_{3}$ films of four different thicknesses grown by two different techniques.

vacancies and $\mathrm{Zn}$ interstitial atoms primarily dominate the conduction characteristics of $\mathrm{ZnO}$. The electrical conductivity in $\mathrm{ZnO}: \mathrm{Al}$ films is higher than that of pure $\mathrm{ZnO}$ film, due to the contribution from $\mathrm{Al}$ ions on substitution sites of $\mathrm{Zn}$ ions and $\mathrm{Al}$ interstitial atoms, as well as from $\mathrm{O}$ vacancies and $\mathrm{Zn}$ interstitial atoms. Coutts et al. [18] have demonstrated that the conductivity of a TCO may be increased without compromising the optical properties by increasing the mobility, rather than the free-carrier concentration. This demonstrates that RF sputtering from a ceramic target is better suited for photovoltaic devices, rather than other techniques.

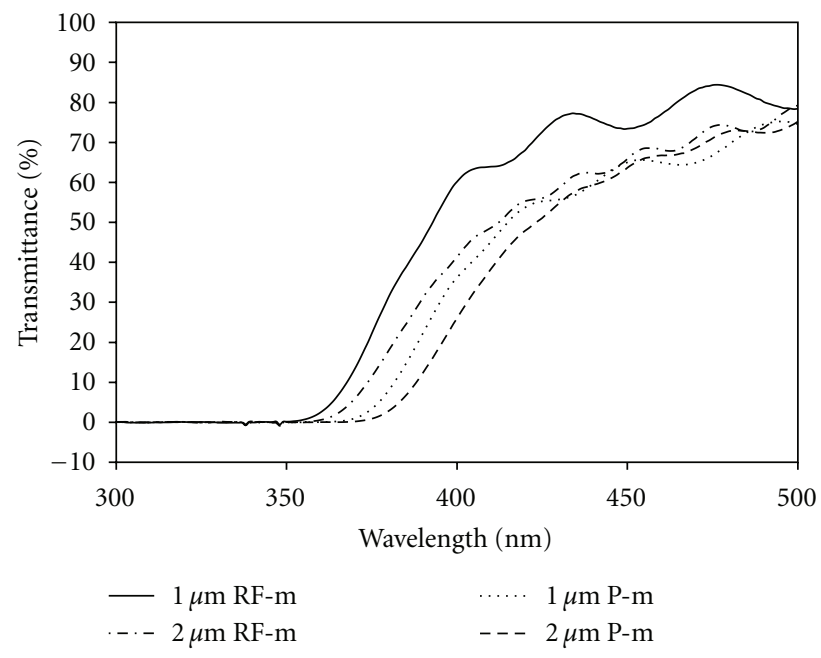

FIgure 11: Optical transmission for the $\mathrm{ZnO}: \mathrm{Al}_{2} \mathrm{O}_{3}$ films of two different thicknesses grown by two different techniques.

Despite similar carrier concentration in films of 1.0 and $2.0 \mu \mathrm{m}$ thickness for both growth techniques, some difference may be noted in mobility: $10.3 \mathrm{~cm}^{2} / \mathrm{V} \cdot \mathrm{s}$ for the RF sputtered from ceramic targets and $3.0 \mathrm{~cm}^{2} / \mathrm{V} \cdot \mathrm{s}$ for the pulsed magnetron sputtering films grown from powder targets. Collectively (from Tables 2 and 4), the films grown from the ceramic targets using RF magnetron sputtering exhibited much preferable electrical characteristics, whereas lower sheet resistance and resistivity and higher mobility and carrier concentration have a constant trend with increased thicknesses. 


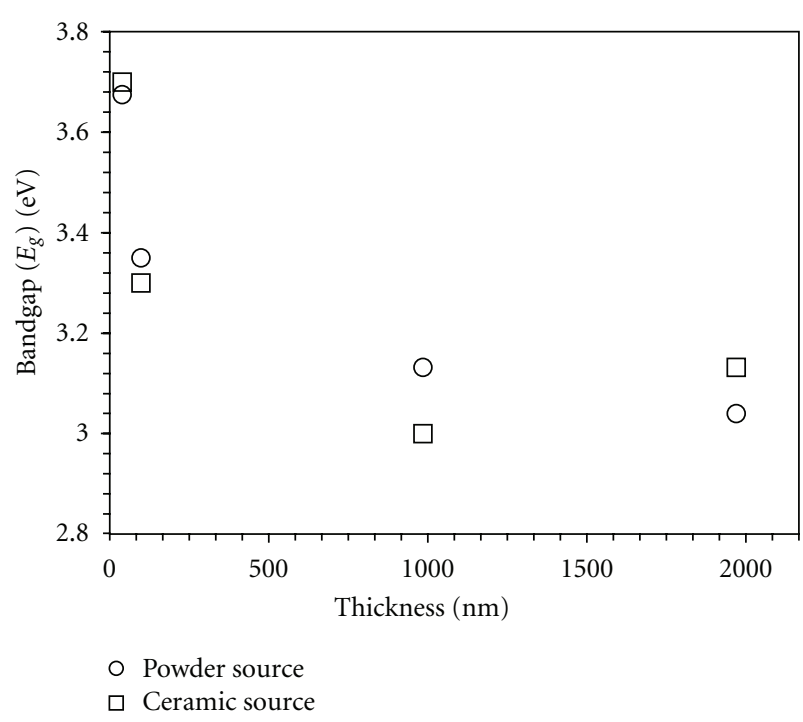

FIGURE 12: Variation of $E_{g}$ with thickness for both growth methods.

\section{Acknowledgments}

The author would like to acknowledge the support of the Surface Engineering Group at the University of Salford, Manchester, UK, for providing the samples grown from Powder Target, namely, Dr. Peter Kelly. Dr. Osama Abu-Zeid of Mechanical Engineering at the UAE University has played a crucial role. Further acknowledgement goes to Dr. Falah Hasoon at the National Renewable Energy Laboratory for help provided to the growth of the samples from the Ceramic Target and providing comparative analysis tools. Special thanks are given to Dr. Mowafak Al-Jassim for his insight and support.

\section{References}

[1] P. Nunes, A. Malik, B. Fernandes, E. Fortunato, P. Vilarinho, and R. Martins, "Influence of the doping and annealing atmosphere on zinc oxide thin films deposited by spray pyrolysis," Vacuum, vol. 52, no. 1-2, pp. 45-49, 1999.

[2] D. Goyal, P. Solanki, B. Marathe, M. Takwale, and V. Bhide, "Deposition of aluminum-doped zinc oxide thin films by spray pyrolysis," Japanese Journal of Applied Physics A, vol. 31, no. 2, pp. 361-364, 1992.

[3] M. Islam and J. Podder, "Optical properties of $\mathrm{ZnO}$ nano fiber thin films grown by spray pyrolysis of zinc acetate precursor," Crystal Research and Technology, vol. 44, no. 3, pp. 286-292, 2009.

[4] M. Hiramatsu, K. Imaeda, N. Horio, and M. Nawata, "Transparent conducting $\mathrm{ZnO}$ thin films prepared by $\mathrm{XeCl}$ excimer laser ablation," Journal of Vacuum Science and Technology A, vol. 16, no. 2, pp. 669-673, 1998.

[5] T. Minami, K. Oohashi, S. Takata, T. Mouri, and N. Ogawa, "Preparations of $\mathrm{ZnO}$ :Al transparent conducting films by d.c. magnetron sputtering," Thin Solid Films, vol. 193/194, no. 2, pp. 721-729, 1990.

[6] Y. Igasaki and H. Saito, "The effects of deposition rate on the structural and electrical properties of $\mathrm{ZnO}: \mathrm{Al}$ films deposited on (1120) oriented sapphire substrates," Journal of Applied Physics, vol. 70, no. 7, pp. 3613-3619, 1991.

[7] C. Y. Lu, S. P. Chang, S. J. Chang et al., "ZnO nanowire-based oxygen gas sensor," IEEE Sensors Journal, vol. 9, no. 4, pp. 485489, 2009.

[8] P. J. Kelly, Y. Zhou, and A. Postill, "A novel technique for the deposition of aluminium-doped zinc oxide films," Thin Solid Films, vol. 426, no. 1-2, pp. 111-116, 2003.

[9] P. J. Kelly and R. D. Arnell, "Development of a novel structure zone model relating to the closed-field unbalanced magnetron sputtering system," Journal of Vacuum Science and Technology A, vol. 16, no. 5, pp. 2858-2869, 1998.

[10] P. J. Kelly and R. D. Arnell, "The influence of magnetron configuration on ion current density and deposition rate in a dual unbalanced magnetron sputtering system," Surface and Coatings Technology, vol. 108-109, pp. 317-322, 1998.

[11] B. D. Cullity, Elements of X-Ray Diffraction, Addison-Wesley, Boston, Mass, USA, 2nd edition, 1987.

[12] N. F. Mott and E. A. Davis, Electronic Process in Non-Crystalline Materials, Oxford University Press, Oxford, UK, 1979.

[13] Joint Committee on Powder Diffraction Standards, Card 361451.

[14] L. I. Berger, Semiconductor Materials, CRC Press, Boca Raton, Fla, USA, 1997.

[15] B. E. Sernelius, K.-F. Berggren, Z.-C. Jin, I. Hamberg, and C. G. Granqvist, "Band-gap tailoring of $\mathrm{ZnO}$ by means of heavy $\mathrm{Al}$ doping," Physcial Review B, vol. 37, no. 17, pp. 10244-10248, 1988.

[16] T. J. Couts, X. Wu, W. P. Mulligan, and J. M. Webb, "Highperformance, transparent conducting oxides based on cadmium stannate," Journal of Electronic Materials, vol. 25, no. 6, pp. 935-943, 1996.

[17] Y. Zhou, P. J. Kelly, A. Postill, O. Abu-Zeid, and A. A. Alnajjar, "The characteristics of aluminium-doped zinc oxide films prepared by pulsed magnetron sputtering from powder targets," Thin Solid Films, vol. 447-448, pp. 33-39, 2004.

[18] T. J. Coutts, D. L. Young, and X. Li, "Characterization of transparent conducting oxides," MRS Bulletin, vol. 25, no. 8, pp. 5865,2000 . 

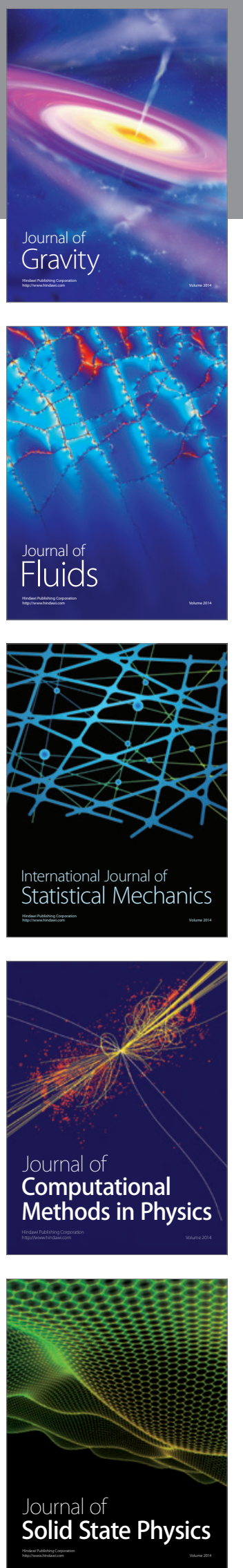

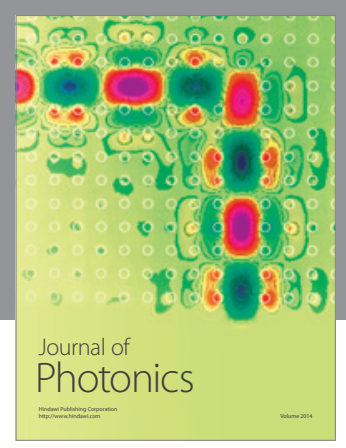

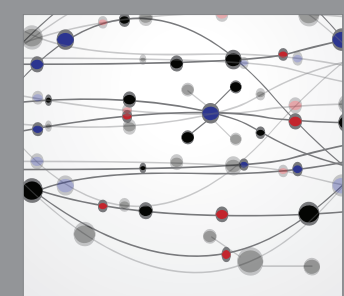

The Scientific World Journal
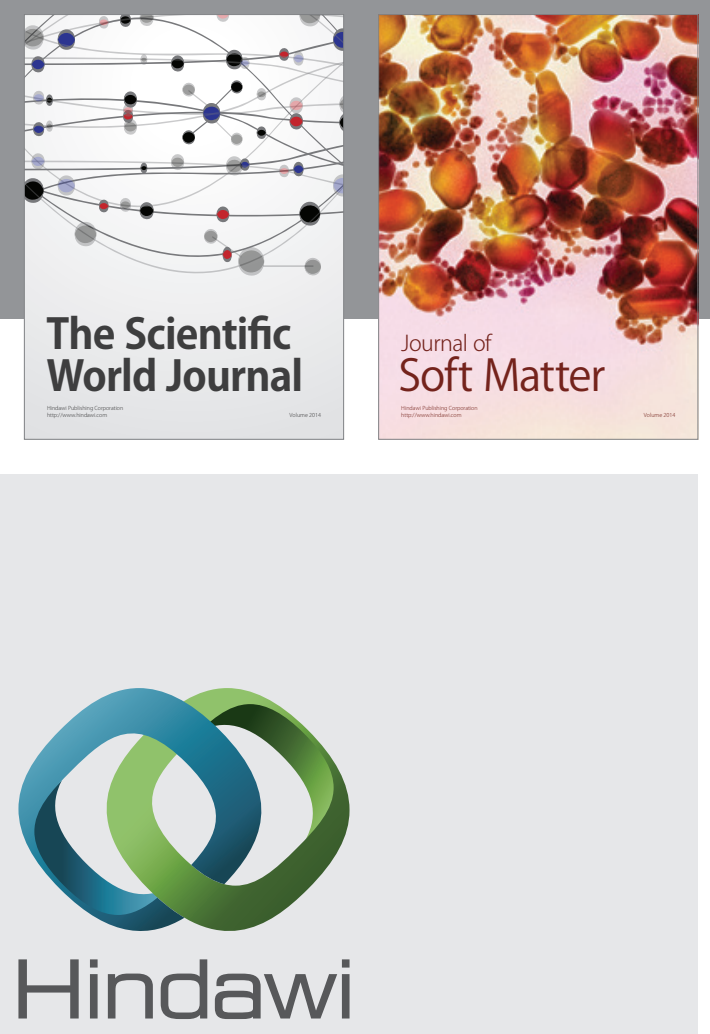

Submit your manuscripts at

http://www.hindawi.com
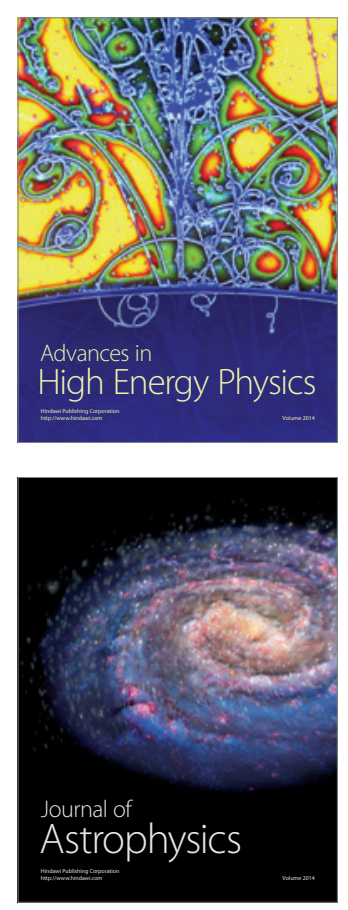
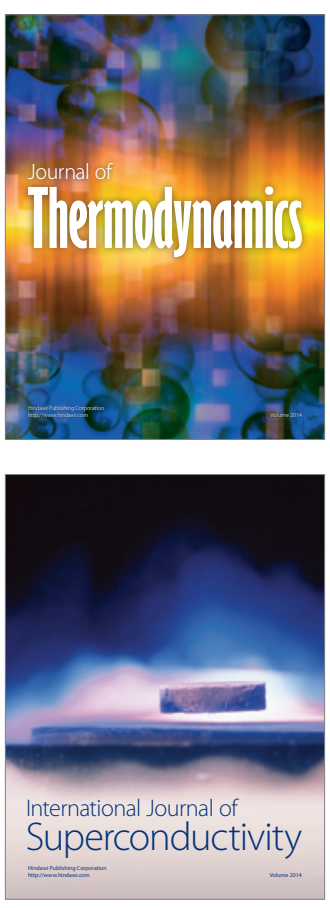
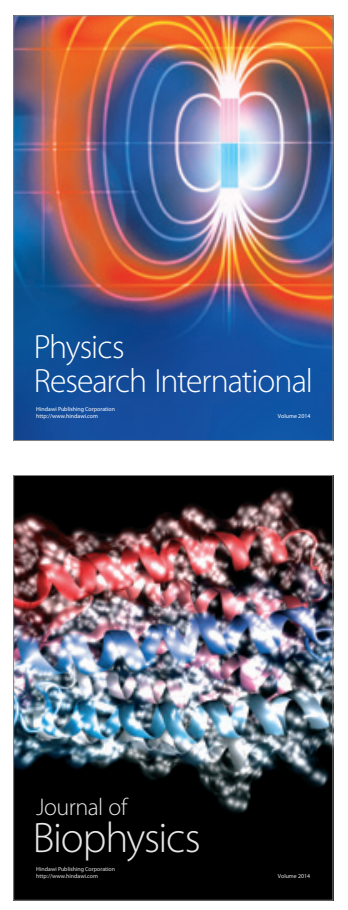
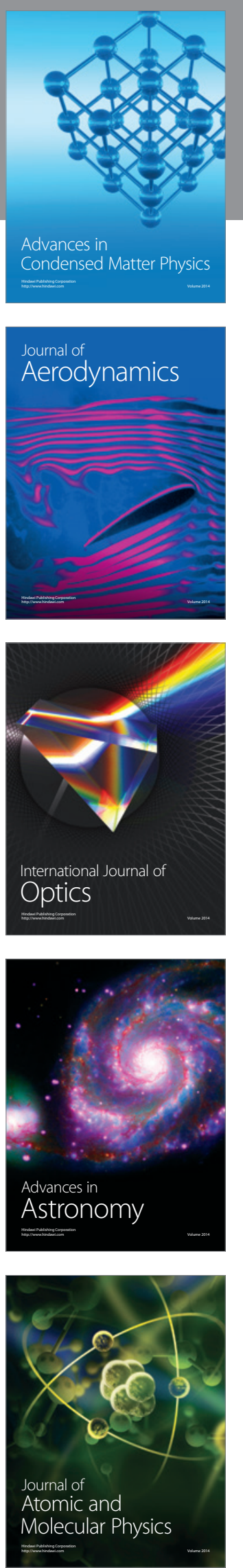